\title{
Cidades na era Lula \\ o lento abandono dos processos participativos
}

\author{
Fernando Luiz Lara ${ }^{1}$
}

\begin{abstract}
Resumo
Os protestos que varreram o país em junho de 2013 nos deixaram a certeza de que apesar de todos os avanços da Era Lula (crescimento econômico com distribuição de renda e estabilidade política), as cidades brasileiras não estão melhores do que há 10 anos. Enquanto, por um lado, avançamos em áreas como acessibilidade e saneamento de vilas e favelas, por outro lado, gastamos bilhões para subsidiar o automóvel quando deveríamos pensar no transporte de 2050, não no de 1950. Este artigo analisa os principais modelos de intervenção urbana das últimas cinco décadas, suas convergências e divergências com os processos que definem a gestão do espaço urbano na Era Lula.
\end{abstract}

\section{Palavras-chave}

Democracia participativa, urbanismo, Minha Casa Minha Vida, favelas, Habitação Social.

Recebido em 15 de outubro de 2013

Aprovado em 22 de março de 2014

LARA, Fernando. Cidades na era Lula: o lento abandono dos processos participativos. Revista do Instituto de Estudos Brasileiros, Brasil, n. 58, p. 245-262, jun. 2014.

DOI: http://dx.doi.org/10.11606/issn.2316-901X.v0i58p245-262

1 Universidade do Texas (UT, Austin, Texas, EUA). 


\title{
Cities in Lula's Era The Slow Death of Participatory Processes
}

\author{
Fernando Luiz Lara
}

\begin{abstract}
The protests that took over Brazil in June 2013 left us assured that despite all the advances of the Lula's Era (economic growth with income distribution and political stability), Brazilian cities are not better than 10 years ago. While on one hand we improved in areas such as accessibility and sanitation of informal settlements, on the other hand we spent billion to subsidize the car when we should be thinking about the transportation for 2050, not 1950. This article examines the main models of urban intervention of the last five decades, their convergencesand divergences with the processes that define the urban policies of the Lula Era.
\end{abstract}

Keywords

Participatory democracy, urbanism, favelas, social housing. 


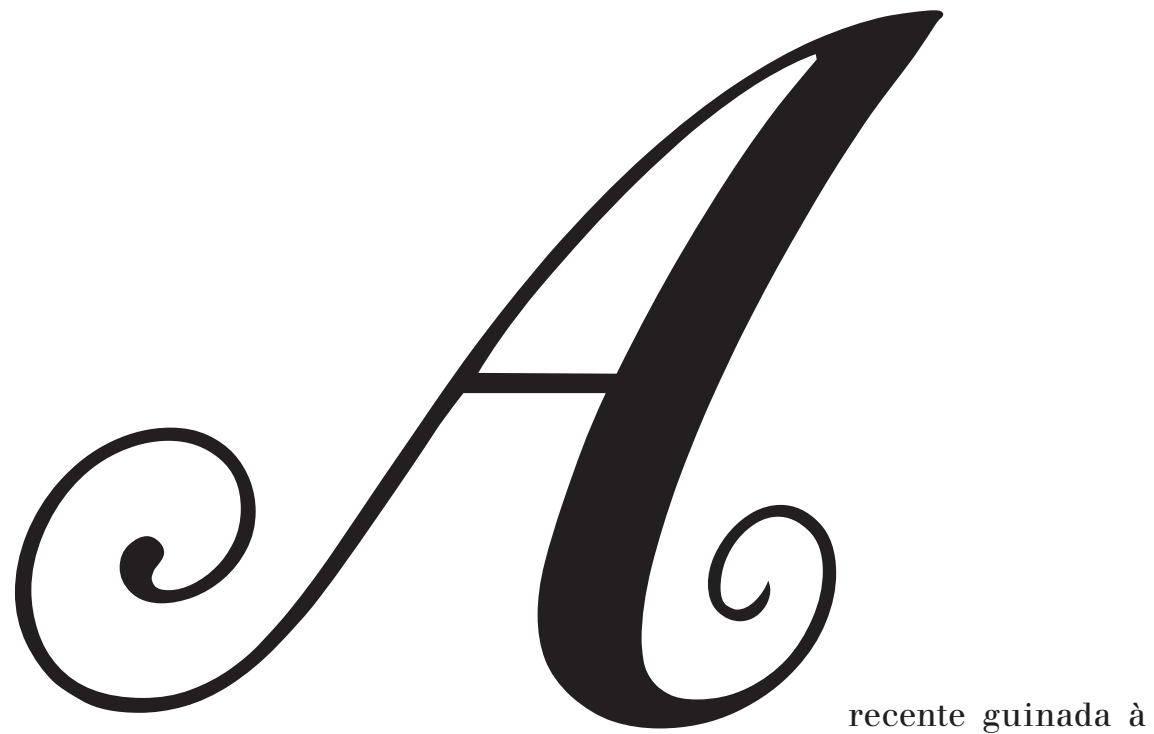

esquerda na política latino-americana criou várias oportunidades de melhorias para o setor informal que compreende uma parte significativa de todas as grandes cidades do continente. No Brasil, o governo Lula investiu bilhões de reais em infraestrutura nas favelas, principalmente com obras de acessibilidade (abertura de ruas) e esgotamento sanitário. No entanto, à medida que avançamos no século XXI, fica claro que o paradigma desenvolvimentista ainda vigente precisa ser reavaliado com base na constante mudança das condições sociais e econômicas ${ }^{2}$. Falta projeto, tanto político quanto técnico, para guiar as urgentes e necessárias melhorias no espaço das cidades. Enquanto é evidente que o modelo de planejamento tecnocrático dos anos 1960 e 1970 já foi há muito superado, um segundo modelo baseado na participação popular foi testado nos anos 1990 e gradualmente passou a ser marginalizado desde então.

Este artigo analisa as transformações nos modelos de intervenção para tentar entender um pouco melhor as oportunidades e os desafios que cada modelo comporta e o que se passou nos últimos 10 anos - a chamada Era Lula. No momento em que as ruas gritam por uma cidade melhor, torna-se fundamental olhar para as origens do urbanismo brasileiro na esperança de que os seus sucessos serão combinados e seus fracassos expurgados no futuro próximo.

2 LARA, Fernando. O paradigma do Asfalto. Revista Forum: um outro mundo em debate, São Paulo, n. 106, p. 42-4,4, jan. 2012. 


\section{Breve história da informalidade brasileira}

O Grupo Habitat das Nações Unidas define uma favela como assentamentos onde estão presentes uma combinação de cinco vulnerabilidades, a saber: falta de água potável; ausência de saneamento; insegurança relativa à posse ou propriedade; precariedade estrutural; e alta densidade/pouca privacidade ${ }^{3}$.

Embora atualmente a maioria das favelas no Brasil tenha acesso à água potável e à energia elétrica (90\% de toda a população urbana, em 2000, de acordo com Nabil Bonduki ${ }^{4}$, apenas a metade tem saneamento adequado. Além disto, a maior parte das famílias nas favelas não tem título de propriedade ${ }^{5}$ e as habitações são bastante precárias ${ }^{6}$. Afora todas essas vulnerabilidades físicas, as favelas enfrentam o estigma social que associa os seus habitantes com a marginalidade, embora a maioria seja de trabalhadores não qualificados com baixa remuneração, quase sempre as maiores vítimas da violência urbana ${ }^{7}$.

Para compreender a dimensão do problema precisamos lembrar que, em 1950, o número de pessoas vivendo nas cidades brasileiras era de 21 milhões (37\% da população total), enquanto que em 2010 esse número ficou acima dos 170 milhões (85\% dos 195 milhões de habitantes). Isto significa que no curso de sessenta anos as cidades brasileiras foram obrigadas a expandir-se para receber 150 milhões de pessoas. O que vemos hoje é resultado desta expansão sem precedentes, as respostas formais e informais para a falta de habitação a preços acessíveis.

3 UNITED NATIONS HUMAN SETTLEMENTS PROGRAMME (UN-Habitat). The Challenge of Slums: Global Report on Human Settlements. New York: United Nations, 2003 .

4. BONDUKI, Nabil. Política habitacional e inclusão social no Brasil: revisão histórica e novas perspectivas no governo Lula. ARQ URB. Revista Eletrônica de Arquitetura, São Paulo, n. 1, 2008, p 70-104. Disponível em: <http://www.usjt.br/arq.urb/ numero_ol.html>. Acesso em: zo abr. 2014.

5 ROLNIK, Raquel; KLINK, Jeroen. Crescimento econômico e desenvolvimento urbano: por que nossas cidades continuam tão precárias?. Novos estudos CEBRAP, São Paulo, n. 89, mar. 2011. Disponível em: < http://www.scielo.br/scielo. php?script $=$ sci_arttext\&pid $=$ So101-33002011000100006\&lng $=$ pt\&nrm $=i s o>$. Acesso em: 15 maio 2014. DOI: http://dx.doi.org/10.1590/So101-33002011000100006.

6 INSTITUTO BRASILEIRO DE GEOGRAFIA E ESTATÍSTICA (IBGE). Aglomerados subnormais: primeiros resultados. Disponível em: <http://www.ibge.gov.br/home/ estatistica/populacao/censo2010/aglomerados_subnormais/default_aglomerados_ subnormais.shtm. Acesso em: 10 jan. 2013.

7 PERLMAN, Janice. Favela: Four Decades of Living on the Edge in Rio de Janeiro, New York: Oxford University Press, 2010. 
Olhando para o século XX, percebemos o Estado brasileiro muitas vezes trabalhando com as políticas que ficaram aquém, muito aquém da dimensão do desafio ${ }^{8}$. O governo Vargas, por exemplo, construiu 242 mil unidades habitacionais entre 1937 e 1954, o suficiente para 800 mil pessoas, ou cerca de $10 \%$ da população urbana do país em $1950^{9}$. Esses conjuntos habitacionais, no entanto, foram financiados pelos sindicatos (Instituto de Aposentadoria e Pensões - IAPs) e beneficiaram apenas os empregados de cada setor. Com uma parcela significativa da população ativa trabalhando na economia informal, as favelas continuaram crescendo.

Em seguida, conforme nos lembra Ana Paula Kouri, o investimento em habitação popular foi praticamente zerado no final dos anos 1950.

No início do governo de Jânio Quadros, já havia a percepção de que estava em marcha uma crise social em larga escala, e que o problema habitacional e urbano agravava-se, expondo a estabilidade política e a própria democracia. Embora as inversões federais no setor habitacional tenham sido sempre pouco significativas, nos anos 1960 os órgãos federais que tradicionalmente responderam pela produção de unidades, como os institutos de previdência e a Fundação da Casa Popular, tiveram um desempenho ainda mais insignificante. Justamente próximo ao ponto de inversão da curva demográfica de população rural e urbana no país, os institutos de previdência foram mobilizados para a construção de Brasília, enquanto a Fundação da Casa Popular, que esbarrou sempre na falta de recursos, o que a tornava pouco operante desde a sua criação em 1946, não produziu unidades na década de $1960 .^{10}$

Em resposta a essa situação, o governo militar criou, em 1967, o Banco Nacional da Habitação. Com recursos do FGTS e das contas de poupança, o BNH financiou mais de 6 milhões de unidades entre 1967 e 1986, o suficiente para abrigar 20\% da população urbana do país

8 FISCHER, Brodwyn. A Poverty of Rights: Citizenship and Inequality in TwentiethCentury Rio de Janeiro. Stanford: Stanford University Press, 2008.

9 BONDUKI, Nabil. Habitação Social na vanguarda do movimento moderno no Brasil. In: GUERRA, Abílio. Textos fundamentais sobre história da arquitetura moderna brasileira. v. 2, São Paulo: Romano Guerra, 2010.

10 KOURY, Ana Paula. A política urbana e a questão social: Quitandinha, o que restou? Arquitextos, São Paulo, 2013. Disponivel em: <http://vitruvius.es/revistas/read/ arquitextos/14.159/4846>. Acesso em: zo abr. 2014 
em $1980^{11}$. Dentro do BNH foi montada uma estrutura de avaliação de projetos que serviu para formar dezenas de técnicos e aos poucos foi replanejando o país inteiro. O principal problema do $\mathrm{BNH}$ foi o fato de que só eram financiadas unidades novas que estavam fora do alcance dos 20\% mais pobres e, além disso, contribuíram para uma expansão descontrolada do tecido da cidade na busca de terra barata disponível.

Vicente Del Rio lembra que "o planejamento nos anos 1960 buscou demolir os assentamentos informais e realocar as famílias de baixa renda em conjuntos habitacionais na periferia longínqua das cidades, [...] causando mais problemas do que soluções". ${ }^{12}$ Apesar dos problemas desta abordagem já serem conhecidos, o BNH acelerou a "erradicação de favelas e a remoção dos moradores para conjuntos habitacionais que, devido ao alto custo da terra no centro da cidade, foram construídos longe da infraestrutura e das oportunidades de emprego existentes". ${ }^{13}$ Qualquer paralelo com o atual programa "Minha Casa Minha Vida" não é mera coincidência, ambos compartilham a mesma lógica desenvolvimentista com pouca ou nenhuma sensibilidade para questões sociais ${ }^{14}$.

A matemática financeira também não ajudava, nem um pouco, na melhoria da qualidade dos espaços urbanos. As empresas de construção buscavam no BNH os recursos para construir de acordo com o potencial econômico dos públicos-alvo. Sendo o público alvo uma determinada faixa salarial de classe média, o BNH financiaria um máximo de $\mathrm{X}$ por unidade, requerendo um mínimo de Y metros quadrados.

Basicamente, o BNH ditava o quanto pagaria por metro quadrado de construção para cada faixa de renda. Esse processo deu às empresas de construção um incentivo para construir o mais barato possível. Trabalhando com o dinheiro alheio, uma vez que a hipoteca seria automaticamente transferida para os compradores, o lucro era a diferença entre o montante recebido do BNH e o custo real. Em um contexto de déficit habitacional agudo esta lógica funcionou como capitalismo sem risco, ou pior ainda, como capitalismo sem risco com forte incentivo para se construir habitações da forma mais barata (e pior) possível.

11 BONDUKI, Nabil. Política habitacional e inclusão social no Brasil: revisão histórica e novas perspectivas no governo Lula, op. cit.; DEL RIO, Vicente. Introduction. In:

SIEMBIEDA, William (eds.). Contemporary Urbanism in Brazil: Beyond Brasilia. Gainesville: University of Florida Press, 2009.

12 DEL RIO, op. cit., p.12.

13 Idem, ibidem, p.16.

14 ROLNIK, Raquel; KLINK, Jeroen, op. cit.; LARA, Fernando. Arquitetura Quae Sera Tamem. Cadernos PROARQ, Rio de Janeiro, n. 17, p. 9-21, 2011. 
O "milagre econômico" da década de 1970 deu aos militares e tecnocratas no poder a confiança na ideia de que o crescimento econômico acabaria por atingir os mais pobres. O sucesso do planejamento de Curitiba onde um plano inteligente de Jorge Wilheim, escolhido por concurso em 1965, foi devidamente amparado pelos governos locais e implementado com mão de ferro pelo grupo de Jaime Lerner, passando a servir de modelo para todo o país. Vale lembrar aqui as críticas de autores nacionais e internacionais ao planejamento tecnocrático de Curitiba, com pouquíssima ou nenhuma forma de participação ${ }^{15}$. Enquanto isso, a desigualdade continuou aumentando, explodindo na "década perdida" dos anos 1980. Com o retorno do governo civil, em 1985, o BNH foi extinto, com grave perda de memória institucional e capacidade gerencial ${ }^{16}$. $\mathrm{O}$ planejamento centralizado tinha seus dias contados, mas se percebe agora que, na ânsia por mudar um sistema fortemente identificado com a ditadura militar, jogamos o bebê fora junto com a água do banho.

O vazio criado pela extinção do BNH em 1986 seria exacerbado pela Constituição de 1988 que dava aos municípios a responsabilidade pelos projetos de habitação e urbanização sem que estes tivessem preparo ou recursos para tanto. Com todos os seus erros e distorções, o BNH era melhor do que a total ausência de política urbana. Mas nem tudo estava perdido. A mesma Constituição de 1988 também instituiu o conceito de que a terra urbana deve ter uma função social. "A função social da propriedade determina que o bem-estar da comunidade é mais importante do que os direitos de propriedade privada, e que o uso do espaço urbano deve ser socialmente justo". ${ }^{17}$

Embora a "função social" ditada pela Constituição não tenha um impacto direto sobre o planejamento da cidade, seu princípio orientou a redação da Lei Lederal no 10257/2001, conhecida como Estatuto das Cidades. Debatida no Congresso, na academia e em seminários públicos

15 IRAZABAL, Clara. City Making and Urban Governance in the Americas: Curitiba and Portland. London: Ashgate, 2005.; LARA, Fernando. Beyond Curitiba: The Rise of a Participatory Model for Urban Intervention in Brazil. Urban Design International, v. 2/15, p. 119-128, Summer 2010. DOI: http://dx.doi.org/10.1057/udi.2010.9; MOORE, Steven. Alternative Routes to the Sustainable City: Austin, Curitiba, and Frankfurt. Lanham: Lexington Books, 2007.

I6 BONDUKI, Nabil. Política habitacional e inclusão social no Brasil: revisão histórica e novas perspectivas no governo Lula, op. cit.

17 MACEDO, Joseli. Urban Land Policy and New Tenure Paradigms: Legitimacy vs. Legality in Brazilian Cities. Land Use Policy, v. 25, p. 259-270, 2008. DOI: http:// dx.doi.org/10.1016/j.landusepol.2007.08.001. 
durante toda a década de 1990, o Estatuto das Cidades serve como marco legal para intervenção nos assentamentos informais ${ }^{18}$.

Entre as muitas ferramentas de planejamento descritas pela lei está a criação de uma categoria de zoneamento especial para as favelas. As ZEIS (Zona Especial de Interesse Social) permitem que posturas municipais sejam flexibilizadas nessas áreas (desde que aprovadas pela Câmara Municipal e pela prefeitura como qualquer mudança no zoneamento), o que por sua vez supera os obstáculos legais para a legalização e oferta de infraestrutura. Por exemplo, mesmo quando os "lotes" ou as "ruas" não atendem às dimensões mínimas exigidas por lei (e eles raramente o fazem nas favelas), a cidade pode oferecer serviços como coleta de água, luz, esgoto e lixo se (e somente se) essa área for delimitada como ZEIS. Mais do que a prestação de serviços, a ZEIS também garante alguma segurança jurídica para os habitantes da região, funcionando como um reconhecimento oficial das comunidades e tornando a reintegração de posse e a consequente expulsão impossível sem a aprovação da mudança de zoneamento pela Câmara Municipal e pela prefeitura.

Depois de 1988 muitas cidades (principalmente as capitais administradas por gestões de esquerda) iniciaram programas visando melhorar a infraestrutura das áreas mais pobres, mas, com exceção de Curitiba, nenhuma cidade brasileira possuía planos eficientes para gerenciar o crescimento ${ }^{19}$.

Concomitantemente, todas as instâncias de gestão metropolitanas foram desmontadas. Qualquer tentativa de conter a expansão periférica (usando as leis de zoneamento, cinturões verdes e incentivos para densificar áreas já bem servidas de infraestrutura) se torna inútil por regulamentos diferentes em um município vizinho, com relações incestuosas entre líderes políticos e empreendedores gananciosos.

No entanto, duas experiências a partir dos meados dos anos 1990, o Favela-Bairro no Rio de Janeiro e o Orçamento Participativo em Belo Horizonte e Porto Alegre (este último já bastante discutido na literatura $^{20}$ ), foram importantes referências de novas políticas urbanas.

18 FERnANDES, Edesio. Constructing The "Right To The City" In Brazil. Social \& Legal Studies, v. 16(2), p. 201-219, 2007. DOI:http://dx.doi.org/10.1177/og64663907076529.

19 LARA, Fernando. op. cit. 2010.; MOORE, Steven. op. cit.

20 WOOD, Terence; MURRAY, Warwick. Participatory Democracy in Brazil and Local Geographies: Porto Alegre and Belo Horizonte Compared. European Review of Latin American and Caribbean Studies, Amsterdam, n. 83, p. 19-41, out. 2007. 


\section{Rio de Janeiro - Favela-Bairro}

Em 1994, o Rio de Janeiro largava na frente das outras cidades brasileiras com o programa Favela-Bairro. A ideia era reconhecer "a importância social, cultural e política das favelas na cidade, considerando estas aglomerações como parte da estrutura urbana e buscando a sua integração com a cidade oficial". ${ }^{21}$ A ideia de que os moradores das favelas têm "direito à cidade" (como articulou Lefebvre em 1968) se tornaria língua franca em quase todas as intervenções posteriores. Mais interessante ainda é perceber que o concurso não pedia soluções, mas, sim, metodologias. A prefeitura assumia que não havia muitos precedentes, que esta era uma experiência pioneira, e que era preciso criar literatura a respeito das experiências em intervenções em áreas informais.

Em 1948, os assentamentos informais alojavam 7\% da população do Rio de Janeiro ou 139 mil pessoas. Este número subiria para 10\% em 1960 e $13 \%$ em 1970. Nesse ponto, as favelas tinham se tornado uma questão importante e os governos conservadores nomeados pela ditadura militar desalojaram 175 mil pessoas das áreas do sul do Rio de Janeiro, deslocando-os para a periferia oeste da metrópole ${ }^{22}$. A infame Cidade de Deus, cuja história virou filme em 2002, é resultado de um desses despejos. No entanto, durante a "década perdida" dos anos 1980 as favelas do Rio de Janeiro cresceram ainda mais rápido, atingindo 16\% da população da cidade em 1990 e 19\% em 2000, quebrando a barreira de um milhão de habitantes em 600 assentamentos diferentes ${ }^{25}$.

Foi neste cenário de pobreza e vulnerabilidade social que a cidade sediou a Rio-92, a Conferência das Nações Unidas sobre Meio Ambiente e Desenvolvimento. Dentro da conferência as conversas giraram em torno da sustentabilidade ambiental, mas nas ruas a questão da sustentabilidade social pairava sobre todos, visitantes e anfitriões. O Exército Brasileiro foi acionado para controlar as favelas e os soldados eram vistos patrulhando as fronteiras entre o morro e $o$ asfalto.

21 DUARTE, Cristiane; MagalHãeS, Fernanda. Upgrading Squatter Settlements into City Neighborhoods: The Favela-Bairro Program in Rio de Janeiro. In: DEL RIO, Vicente; SIEMBIEDA, William (Eds.). op. cit., p. 266-29o; FIORI, Jorge; BRANDÃO, Zeca. Spatial Strategies and Urban Social Policy: Urbanism and Poverty Reduction in the Favelas of Rio de Janeiro. In: HERNANDEZ, Felipe; KELLET, Peter (Eds.). Rethinking the Informal City. London: Bergham Books, 2010. VALLADARES, Licia. A invenção da favela: do mito de origem a favela.com. Rio de Janeiro: FGV, 2005.

23 Idem, ibidem. 
Coincidência ou não, no ano seguinte a cidade iria anunciar uma nova política de habitação, com base na integração, na acessibilidade e na melhoria do espaço público: o programa Favela-Bairro. O concurso lançado em 1994 solicitava ideias para intervenção em assentamentos informais de médio porte, comunidades entre 500 e 2.500 famílias que abrigam 600.000 pessoas, ou $60 \%$ de informalidade do Rio de Janeiro ${ }^{24}$. A ideia era que as maiores favelas, como a Rocinha e o Complexo do Alemão, exigiriam planos mais complexos, enquanto pequenos assentamentos não dariam tanto resultado.

Trinta e dois escritórios locais apresentaram propostas e quinze foram selecionados (um para cada uma das quinze áreas prioritárias). A primeira fase do Favela-Bairro (1994-1997) teve uma abordagem integrada e multissetorial, em que a acessibilidade e conectividade seriam abordados pela construção de ruas e de espaço público, o que por sua vez possibilitariam a passagem da rede de esgoto, a relocalização do menor número possível de famílias e a construção de novas moradias para estas dentro de cada comunidade. Em alguns casos, os projetos contemplavam centros comunitários e espaços comerciais. A legalização fundiária deveria vir em seguida, mas vinte anos depois continuamos com números pífios neste quesito ${ }^{25}$.

A implementação do Favela-Bairro foi inicialmente financiada pela prefeitura do Rio de Janeiro e mais tarde por um empréstimo do Banco Interamericano de Desenvolvimento. Outras fontes de financiamento foram a Caixa Econômica Federal e a União Europeia em 1997, e o Governo Federal em 1998.

Em sua primeira versão, o Favela-Bairro teve investimento total no valor de 300 milhões de dólares que beneficiaram de meio milhão de pessoas em 146 assentamentos, com a melhoria de 500 quilômetros de estradas e calçadas, a construção de 160 quilômetros de novas ligações de esgoto e 500 mil metros quadrados de instalações desportivas.

Mas, como tantos outros projetos de infraestrutura urbana, o Favela-Bairro sofreria reveses políticos. O sucesso de sua primeira fase (1994-1997) catapultou Luiz Paulo Conde de Secretário de Planejamento para a cadeira de prefeito. Quatro anos mais tarde, quando César Maia foi eleito prefeito novamente, o Favela-Bairro foi reduzido de forma significativa, apesar de ter sido Maia o prefeito que lançou o programa em 1993. Vários dos projetos lançados por Maia entre 1994 e 1996 foram

\footnotetext{
24. CONDE, Luis Paulo; MAGALHÃES, Sergio. Favela-Bairro: Rewriting the History of Rio. Rio de Janeiro: Viver Cidades, 2004.

25 FIORI, Jorge; BRANDÃO, Zeca. op.cit.; FERNANDES, Edesio, op. cit.
} 
inaugurados por Conde em 1997 e 2001 e uma identificação muito forte foi formada entre o prefeito arquiteto e o Favela-Bairro.

Melhorias em larga escala dos assentamentos informais teriam que esperar até o segundo mandato presidencial de Luiz Inácio Lula da Silva para serem ressuscitados. Entre 2005 e 2009, o Governo Federal investiu em todo o país 200 bilhões de dólares em infraestrutura, metade em saneamento e melhoria do espaço público. O Programa de Aceleração do Crescimento (PAC) levou 2 bilhões de dólares para a cidade do Rio de Janeiro, seis vezes mais do que o orçamento original do Favela-Bairro ${ }^{26}$.

Enquanto a primeira versão não tratava de unidades habitacionais, intervenções muito maiores como o PAC do Complexo do Alemão incluem moradia para centenas de famílias reassentadas dentro da mesma comunidade. A nova versão do Favela-Bairro, rebatizado Morar Carioca, incorporou melhorias importantes como obrigar as empresas de construção a contratar 40\% da força de trabalho no local, uma estratégia que tem dois grandes impactos: injeta dinheiro na economia local e facilita o diálogo (muitas vezes tenso) entre as equipes de construção e os moradores.

No entanto, processos institucionais de participação nunca foram implementados no Rio de Janeiro ${ }^{27}$. Apesar dos concursos de arquitetura serem certamente o melhor processo para alcançar a qualidade do projeto, a implementação de tais projetos é insuficiente se a comunidade não está envolvida. A maioria dos estudos realizados sobre o Favela-Bairro até o momento ${ }^{28}$ corrobora essas deficiências. A decisão de trabalhar com maior ou menor participação da comunidade ficou a critério dos arquitetos contratados. No caso dos planos diretores elaborados por Jorge Jauregui no Complexo do Alemão e Luiz Carlos Toledo na Rocinha houve significativa participação, o que fez dos projetos muito mais fortes.

26 CAMARA, Andreza A. Franco. Políticas Públicas e o Programa de Aceleração do Crescimento: análise das intervenções no estado do Rio de Janeiro. Revista Brasileira de Políticas públicas, Brasília, v.1, n.7, p. 147-178, dez. 2011. DOI: http://dx.doi. org/10.5102/rbpp.vıiz.1487.

27 CARDoso, Isabel C. da Costa. O Orçamento Participativo do Rio de Janeiro e as Políticas de Planejamento Urbano Estratégico. Revista Em Pauta, Rio de Janeiro, v.6, n. 24, p. 113-138, dez. 2009 .

28 DUARTE, Cristiane; MAGALHÃES, Fernanda. Upgrading Squatter Settlements into City Neighborhoods: The Favela-Bairro Program in Rio de Janeiro, op. cit.; FIORI, Jorge; BRANDÃO, Zeca. op. cit.; SOARES, Fabio; SOARES, Yuri. The Socio-Economic Impact of Favela-Bairro: What do the Data Say? Working Papers, Office of Evaluation and Oversight (OVE), Inter-American Development Bank, Washington, D.C., Aug. 2005. 
Recentemente, em setembro de 2013, acompanhamos o debate sobre a implementação de um teleférico na favela da Rocinha. Utilizado em Medellin, na Colômbia, para áreas onde o controle de gangues rivais dificultava a mobilidade, o teleférico tem a desvantagem de isolar o morador da rua. Toledo discutiu isto com os moradores e os comerciantes da Rocinha, propondo planos inclinados e escadas rolantes como uma solução mais adequada. A comunidade, empoderada pelas discussões e pelas propostas alternativas, tem conseguido adiar a construção do teleférico que é defendida pelo governo estadual.

\section{Belo Horizonte e o Orçamento Participativo}

Entre 1993 e 2008, Belo Horizonte foi governada por uma parceria entre o prefeitos do PT (Partido dos Trabalhadores) e do PSB (Partido Socialista Brasileiro), com alternância de prefeito e vice-prefeito de cada legenda. Tal continuidade, inédita na história recente do Brasil, foi bem sucedida em diversas frontes, mas principalmente no modelo de governança e implementação de obras de infraestrutura urbana. O modelo tem as suas raízes no processo do Orçamento Participativo (OP), em que a cada dois anos a cidade dedica uma parte de seu orçamento de obras públicas para ser votado pela população em uma série de assembleias ${ }^{29}$. A implementação do OP coincide com o fortalecimento da Companhia Urbanizadora e de Habitação de Belo Horizonte (URBEL), uma agência municipal que trata especificamente de infraestrutura nas favelas. Foi criada em 1961 para gerenciar propriedades do município e por isso está envolvida com as favelas de uma forma ou outra há meio século, promovendo principalmente relocações nos primeiros 30 anos de existência. Em 1993, a prefeitura de Belo Horizonte determinou que a URBEL seria responsável pela execução da política municipal de habitação e pela gestão de todas as intervenções nas favelas. Naquele momento a URBEL também herdou uma série de bons planos elaborados pela Superintendência de Desenvolvimento da Região Metropolitana de Belo Horizonte (PLAMBEL), uma autarquia estadual de 1975 a 1996, mas nunca totalmente implementados por conta da falta de vontade política.

29 NYLEN, William. Testing the Empowerment Thesis: The Participatory Budget in Belo Horizonte and Betim, Brazil. Comparative Politics, New York, v. 34, n. 2, p. 127-145, jan. 2002. DOI: http://dx.doi.org/10.2307/4146934; AVRITZKER, Leonardo. Participatory Institutions in Democratic Brazil. Baltimore: John Hopkins University Press, 2009; LARA, Fernando. op. cit., 2010. 
Em 1994, Belo Horizonte começou a executar pequenas intervenções baseadas na ideia de "direito à cidade", financiadas pelo seu próprio orçamento. Por começar pequeno e com um modelo participativo, a cidade de Belo Horizonte teve tempo para planejar, ajustar e testar os processos antes que o PAC de 2005 mudasse completamente a escala e a natureza das intervenções.

Entre 1994 e 2004, a URBEL elaborou 55 Planos Globais Específicos (PGE), que beneficiaram 77 favelas e 283.000 habitantes. Uma vez que o PGE é um pré-requisito para qualquer projeto a ser financiado pelo orçamento participativo, é do interesse de todas as comunidades solicitar e apoiar a elaboração de um plano para a sua favela.

O PGE inclui um levantamento detalhado da situação existente por meio da elaboração de uma série de mapas temáticos de base SIG (Sistemas de Informação Geográfica) que detalham a infraestrutura, a estrutura domiciliar, os dados sócio-econômicos e todo tipo de problemas, desde esgoto a céu aberto e acúmulo de lixo até áreas controladas por traficantes. A elaboração de um PGE é o trabalho de uma equipe interdisciplinar de nada menos do que uma dúzia de profissionais entre engenheiros, arquitetos, sociólogos, profissionais de saúde, economistas e assistentes sociais. O processo envolve inúmeras reuniões com líderes comunitários e várias assembleias em que toda a população é convidada, a fim de se certificar de que todos os problemas são anotados e as prioridades definidas corretamente. Não é necessário dizer que o processo geralmente leva alguns anos até sua conclusão.

Após a conclusão e a aprovação do PGE (com avaliações da URBEL e de outros órgãos municipais afins) este torna-se o plano oficial para aquela área. Qualquer intervenção proposta pelo Orçamento Participativo deve cumprir o que foi ali determinado, bem como projetos apoiados por outras fontes.

De 1994 a 2008, foram alocados 174 milhões de reais do Orçamento Participativo para favelas de Belo Horizonte, gerando 326 projetos, 219 deles concluídos na primeira década do século XXI. A execução desses projetos exige um outro grau de envolvimento da comunidade, pois qualquer construção implica em mudanças na rotina das pessoas e, às vezes, até mesmo alterações em suas residências. A continuidade administrativa é, portanto, um elemento chave no processo, permitindo que a URBEL tivesse tempo para gerenciar cada um desses 300 projetos que muitas vezes se estendem ao longo de vários anos, muito além dos mandatos dos governantes eleitos.

No entanto, os 174 milhões de reais alocados pela via do Orçamento Participativo empalidecem quando comparados com os valores 
dos projetos em curso financiados pelo PAC. A cidade de Belo Horizonte sozinha captou 580 milhões de reais para um conjunto de melhorias em áreas informais rotulado de Vila Viva. Não há dúvida de que a proximidade do prefeito Fernando Pimentel com a então ministra Dilma Rousseff foi decisiva na captação desses fundos. Mas também foi significativo o fato de que Belo Horizonte tinha dezenas de projetos bem desenvolvidos a partir do Orçamento Participativo, prontos para serem licitados e executados.

Entre 2006 e 2010, o Vila Viva construiu grandes intervenções nas maiores favelas da cidade. No aglomerado da Serra, uma comunidade de 48 mil habitantes, o projeto Vila Viva abriu quilômetros de ruas, relocando 1.100 famílias que viviam em áreas propensas a inundações ou deslizamentos de terra. Dessas famílias, 900 decidiram continuar na comunidade, morando em prédios de apartamentos também construídos pelo projeto. A construção destes blocos de apartamentos são o ponto fraco da intervenção. Como a literatura em projeto e planejamento urbano já demonstrou, as áreas comuns dos edifícios para populações de baixa renda tendem a ser foco de conflito, colocando em risco o bem-estar de todo o conjunto. Entrevistas com autoridades municipais realizadas em 2008 e 2009 indicam que as empresas de construção eram resistentes à ideia de casas geminadas ou tipologias mais elaboradas, e o município cedeu a esses argumentos. Estava aí já localizado um problema que agora se mostra muito mais grave: a força da indústria da construção para passar por cima de planos, licenciamentos e negociações elaboradas, impondo o que for mais conveniente para ela. O ponto alto da intervenção no aglomerado da Serra é a gestão dos cursos de água que agora correm livres, permitindo a criação de um parque tripartido, oferecendo instalações de lazer e áreas verdes extremamente necessárias em uma região da cidade cuja densidade é superior a 300 habitantes por hectare.

Por mais que o planejamento tenha sido bem pensado e os canais de participação bem implementados, o processo de licitação sempre foi o “calcanhar de Aquiles" dos projetos de obras públicas em Belo Horizonte. Uma vez que a URBEL termina as planilhas de quantitativos baseadas em um estudo preliminar, o projeto e a construção são contratados a partir do menor lance. Se a construtora vencedora traz um bom arquiteto (como foi o caso de Fernando Maculan no Beco São Vicente; Carlos Teixeira e Flavio Agostini no Parque das Três Águas; ou grupo Horizontes na Pedreira Prado Lopes, três projetos premiados), a qualidade do projeto é alta e os resultados são melhores. Mas se a construtora traz consigo um arquiteto medíocre (que infelizmente é o caso na maioria 
das intervenções do Vila Viva), os resultados são decepcionantes. Mais preocupante é perceber, tanto pelos números quanto pelos relatos de associações comunitárias e de ativistas locais, que os processos participativos foram postos de lado assim que a escala das intervenções foi multiplicada por 10 com o financiamento do PAC ${ }^{30}$. Entre 2002 e 2012, o número de participantes caiu de 44 mil para $35 \mathrm{mil}$ pessoas nas assembleias e o montante destinado ao Orçamento Participativo em Belo Horizonte ficou estacionado: 85 milhões de reais em 2002 e 87 milhões em 2012. Para efeito de comparação, no mesmo período o orçamento geral da prefeitura aumentou 275 !

\section{Cidades na Era Lula: por que não melhoraram?}

É muito difícil neste momento determinar com algum grau de certeza quais foram as decisões que levaram ao abandono dos processos participativos justamente quando Luiz Inácio Lula da Silva governava o país e alcançava um sucesso inquestionável em outros estratos de desigualdade. Fica claro que o ano de 2005 foi um divisor de águas com as mudanças no Ministério da Cidade, em consequência do escândalo do "mensalão". Desde então a ênfase desenvolvimentista, que parece ser tão eficiente em questões como distribuição de renda e pleno emprego, tem deixado sequelas graves nas cidades brasileiras.

O que a literatura atual já trata com desenvoltura é a relação entre o escândalo do "mensalão" e as mudanças no Ministério das Cidades ${ }^{31}$. Em resposta à crise política que se seguiu às denuncias do deputado Roberto Jefferson em 2005, o governo Lula promoveu uma mudança drástica no Ministério das Cidades. A saída do ministro Olívio Dutra e sua equipe marca o abandono dos processos participativos, que eram a bandeira deste que foi prefeito de Porto Alegre entre 1989 e 1993. No

3o ENTRE SEM BATER. Disponível em: <http://entresembater.org.br/remocoes>. Acesso em: 3 out. 2013; BRASIL 247. Em BH Orçamento Participativo vira só papel. Editorial de 23 de abril de 2012. Disponível em: <http://www.brasil247.com/pt/247/ minas247/55659/Em-BH-Or\%C3\%A7amento-Participativo-vira-s\%C3\%B3-papel. htm>. Acesso em: 30 abr. 2014; Entrevista com o vereador Arnaldo Godoy, 25 de fevereiro de 2014 .

31 FLYNN, Peter. Brazil and Lula, 2005: Crisis, Corruption and Change in Political Perspective. Third World Quarterly, London, p. 1221-1267, v. 26, n. 8, 2005. DOI: http://dx.doi.org/10.1080/01436590500400025; VALENÇA, M. M.; BONATES, M. F. The Trajectory of Social Housing Policy in Brazil: From the National Housing Bank to the Ministry of the Cities. Habitat International. Vancouver, v.34, n. 2, p. 165-173, 2010. DOI: http://dx.doi.org/10.1016/j.habitatint.2009.08.oo6. 
sentido diametralmente oposto, o Ministério das Cidades passou a ser conduzido por líderes do Partido Republicano e do Partido Progressista, tradicionalmente ligados à indústria da construção.

O modelo atual privilegia o automóvel e o espraiamento das cidades em busca de terra barata. Chegamos a um ponto em que a construção quase não interessa, vale apenas comprar e vender terra. O programa "Minha Casa Minha Vida", por exemplo, transforma terra barata nas franjas mais longínquas de qualquer região metropolitana em terra cara, as casas por cima pouco contribuindo para lucro do empreendimento.

Este modelo vem carregado de problemas: submete os moradores a horas e horas em ônibus lotados e engarrafamentos homéricos, isola os mais pobres da infraestrutura que ainda é concentrada nas áreas centrais e confunde qualidade de vida urbana com o título de propriedade. Façam o teste do mercado: comparem o valor do aluguel das casas do "Minha Casa Minha Vida" com o valor do aluguel em favelas de áreas centrais de qualquer cidade brasileira e verão onde se vive melhor.

Uma das questões mais perversas do programa é justamente o abandono dos processos participativos em direta oposição ao Plano Nacional de Habitação (PlanHab). Enquanto o PlanHab incentiva a participação local e a diversidade de soluções (em resposta a enorme diversidade de problemas urbanos pelo país afora), o MCMV uniformiza em uma única solução habitacional de inspiração fordista ${ }^{32}$. Mais grave ainda é a transferência de recursos do Fundo Nacional de Habitação de Interesse Social (FNHIS) para o programa MCMV, restringindo significativamente o montante de recursos disponíveis para quaisquer outra solução que não seja a construção de casinhas idênticas na periferia longínqua das grandes cidades. Isto gera outro impacto perverso: apenas as cidades menores e de economia menos dinâmica dispõem de terra barata que justifique a construção do $\mathrm{MCMV}^{33}$. As maiores cidades, nas quais as soluções para Habitação de Interesse Social deveriam se inserir em áreas consolidadas ou de densidade decrescente (como os hipercentros esvaziados), estão completamente desatendidas pela política atual que coloca um programa específico, o MCMV, acima de uma política de

32 KRAUSE, C. et al. Minha Casa Minha Vida, Nosso Crescimento: Onde Fica A Política Habitacional? Texto para discussão 1853, Brasília/Rio de Janeiro: IPEA, 2013.

33 CARDoso, A. L.; ARAGÃO, T. A. Do fim do BNH ao Programa Minha Casa Minha Vida: 25 anos da política habitacional no Brasil. In: CARDOSO, A. L. (Org.). O Programa Minha Casa Minha Vida e seus efeitos territoriais. Rio de Janeiro: Letra Capital, 2013 . 
estado, o PlanHab. A conclusão de Krause ${ }^{34}$ e Nascimento Neto ${ }^{35}$ é de que o MCMV é um programa para gerar emprego e crescimento econômico, não necessariamente para gerar uma cidade melhor.

A longo prazo o processo é ainda mais perverso. Vicente Fox prometeu construir 5 milhões de moradias ao assumir o governo do México, no ano 2000, com um programa chamado INFONAVIT que se parece muito com o MCMV. Tal meta foi cumprida durante o mandato de seu sucessor Felipe Calderon. Depois de doze anos de loteamentos nas mais distantes periferias de Monterrey, Chiuahua, Ciudad Juarez, Guadalaraja e Tijuana, quase $40 \%$ destas casas estão abandonadas e qualquer relação com o alarmante índice de violência não é mera coincidência. No caso brasileiro temos a Cidade de Deus como exemplo, e o filme de Fernando Meirelles mostrou para o mundo inteiro o que pode acontecer quando uma comunidade é removida para áreas completamente isoladas do resto da cidade ${ }^{36}$.

Os protestos de junho de 2013 tiveram o mérito de trazer o problema para o debate nacional. Uma real melhoria no transporte público, seja na redução significativa dos custos ou na melhoria do serviço, teria um efeito transformador na estrutura urbana, porque afetaria o valor da terra. Com transporte público bom e barato, a periferia se valoriza instantaneamente. Isso equivale a uma transferência de renda revolucionária e um impacto ainda maior na qualidade de vida de milhões de brasileiros. Vale notar que a única forma de aumentar a velocidade média das nossas congestionadas vias é com investimento em transporte público. Como alguém disse recentemente, alargar as ruas para resolver o problema do trânsito equivale a afrouxar o cinto para resolver o problema da obesidade.

Mas infelizmente a obsessão desenvolvimentista, que tomou conta do PT no governo federal e se acentua como marca do governo Dilma, continua derramando mais asfalto e mais concreto como solução para

34. KRAUSE, C. Etal. Minha Casa Minha Vida, Nosso Crescimento: Onde Fica A Política Habitacional?, op. cit.

35 NASCIMENTO NETO et al. Conceitos divergentes para políticas convergentes: descompassos entre a Política Nacional de Habitação e o Programa Minha Casa Minha Vida. Revista brasileira de estudos urbanos e regionais, Rio de Janeiro, v.14, n.1, maio 2012.

36 CENTRO DE INVESTIGACIÓN Y DOCUMENTACIÓN DE LA CASA (CIDOC). Estado actual de lavivienda 2oo8. México: Sedesol, Infonavit, Conavi, 20o9; MAYCOTTE, E. Ocupación del suelo habitacional y participación del sector público y privado em La producción de vivienda social en Ciudad Juárez, Chihuahua. Rizoma: revista de cultura urbana de La Agencia para la Planeación del Desarrollo Urbano del Estado de Nuevo León, Nuevo León, n. 8, p.3 6-39, 2008. 
todos os problemas ${ }^{37}$. Enquanto por um lado melhoramos em áreas como acessibilidade e saneamento de vilas e favelas ${ }^{38}$, por outro lado gastamos bilhões para subsidiar o automóvel quando deveríamos estar pensando no transporte de 2050 , não no de 1950 . A pressão popular está nas ruas e só ela, nesta escala, tem força suficiente para se contrapor aos lobbies das montadoras, do asfalto, da construção pesada e outros.

\section{Sobre o autor:}

\section{Fernando Luiz Lara}

Formado em arquitetura na Universidade Federal de Minas Gerais (UFMG) e PhD pela Universidade de Michigan (UM). Atualmente, é Professor Associado da Escola de Arquitetura da Universidade do Texas (UT) em Austin, onde também atua como diretor do Centro de Estudos Brasileiros do Lozano Long Institute of Latin American Studies.

E-mail: fernandolara@utexas.edu

37 LARA, Fernando, op. cit. (2011), p. 9-21.

38 PAES de BARROS, Ricardo et al. Texto para Discussão 1253. In: Determinantes Imediatos da Queda da Desigualdade de Renda Brasileira. Rio de Janeiro: Ipea, 2007. Disponível em: <http://www.ipea.gov.br/portal/index.php?option=com_ content $\&$ view $=$ article $\& i d=4816 \&$ catid $=170 \&$ Itemid $=2$. Acesso em: 30 abr. 2014 . 